\title{
Batch Adsorption Investigation of the Use of Cordia Milleni Carbon for Wastewater Treatment
}

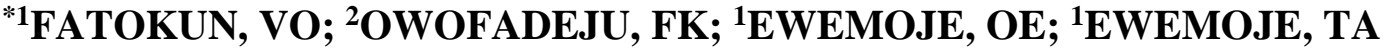 \\ ${ }^{*}$ Agricultural and Environmental Engineering Department, University of Ibadan, Oyo State, Nigeria \\ ${ }^{2}$ Wood Products Engineering Department, University of Ibadan, Oyo State, Nigeria \\ *Corresponding Author Email: fatokun77@gmail.com; Other Authors Email: fem_fadeju@yahoo.com seyiajayi2@yahoo.com \\ tayo_ewemoje@yahoo.co.uk
}

\begin{abstract}
Applicability of low-cost adsorbent from Cordia millenii wood via carbonisation and chemical activation with zinc chloride was examined in this study for the removal of contaminants in textile effluent. The structural pattern of the carbon was examined using SEM equipment (TESCAN VEGA3 (LAB 6)). Batch sorption tests were conducted in wastewater treatment by varying adsorbent contact time with the sorbate from 30 to 120 minutes (at 30minutes intervals) in 200ml of wastewater sample and agitated intermittently at room temperature to facilitate attainment of equilibrium condition. The pore structures of the adsorbent were interconnected with mean diameter size of $9.28 \pm 1.22 \mu \mathrm{m}$. Maximum removal efficiencies of $63.52,64.94,66.78$ and $79.86 \%$ at 120 minutes contact time for iron, zinc, chromium and cadmium respectively were observed. Conductivity, TDS and TS increase with increasing contact time up to 90 minutes before reducing slightly. The removal percentage was more than $50 \%$ at the first 30 minutes of the sorption process for nitrate, turbidity and TSS. The treated wastewater with Activated Cordia millenii Carbon cannot be used for irrigation purpose because of the high value of electrical conductivity in the wastewater which can impede plant growth. It was indicated in the results that abundant, available and renewable adsorbent of Cordia millenii can be used for the removal of contaminants in textile effluents.
\end{abstract}

\section{DOI: https://dx.doi.org/10.4314/jasem.v25i6.13}

Copyright: Copyright (c) 2021 Fatokun et al. This is an open access article distributed under the Creative Commons Attribution License (CCL), which permits unrestricted use, distribution, and reproduction in any medium, provided the original work is properly cited.

Dates: Received: 20 March 2021; Revised: 27 April 2021; Accepted: 07 May 2021

Keywords: Textile wastewater, Cordia millenii, activated carbon, batch sorption, contaminants

The textile industry is one of the important industries which release large amount of wastewater into the environment causing water pollution, which is not only harmful for aquatic life but also mutagenic to human (Mohammed et al. 2010; Lellis et al. 2019). Most of the time, wastewater is disposed indiscriminately on adjacent land leading to percolation and pollution of the subsurface water reservoir (Omotoso and Ewemoje, 2020). Textile industries wastewater contains pollutants which vary in term of concentration and depend on the treatment processes adopted. The textile wastewater, if not treated might cause severe hazardous contamination of water bodies (Slokar and Marechal, 1998). The dyeing and finishing segment of textile industry has been established to be the greatest industrial water pollutant in the world (Kant, 2011). Textile dyes are toxic in nature, highly stable and also difficult to be removed by conventional methods of wastewater treatment (Muluken, 2014). Hassan and Carr (2020), however stated that sometimes the dyes used in the textile industry might not be as highly toxic or carcinogenic as their degradation products. Ineffective and inefficient waste management is one of the major environmental problems confronting many cities in most developing countries (Coker et al. 2009). Over the years, various methods of treating wastewater have been developed, such as chemical precipitation, chemical oxidation or reduction, electrochemical treatment, ion exchange, reverse osmosis, filtration, evaporation recovery, and electrocoagulation. However, most of these methods have significant disadvantages which include high energy requirements, inefficient metal removal, generation of sludge, high cost of equipment and high volume cum low heavy metal concentration of effluents to be treated (Chen et al. 2010; Desta, 2014). Also, conventional methods used for the treatment of contaminated wastewater with heavy metal ions are very expensive (Adie, 2012). Thus, there is the need for the adoption of cheap, economical and locally available alternatives. Adsorption processes are being widely used by various researchers for the removal of contaminants from waste streams utilising activated carbon most often as an adsorbent (Reuben and Miebaka, 2008; Bolade and Sangodoyin, 2018). Many researchers have affirmed the ability of adsorption not only to remove odour and colour but also heavy metals, organic matters, suspended solids and E.coli. Currently, attention is shifting towards naturally 
sourced materials such as locust bean husk (AjayiBanji et al, 2015a), bamboo (Ijaola et al, 2013), cattle bone and horn (Sangodoyin and Ajayi-Banji, 2013), cassava peel (Omotoso and Ewemoje, 2020), snail shells (Bolade and Sangodoyin, 2018), coconut husk (Ajayi-Banji et al, 2015b), wood (Yargicoglu et al. 2014), eggshells (Badrealam et al. 2020), Arachis hypogea shell (Gimba and Bahago, 2004), modified cassava fiber (Okuo and Oviawe, 2007), periwinkle shells (Okuo and Ozoiko, 2001) as adsorbents.

Therefore this study was carried out to investigate the adsorption of contaminants from textile wastewater using a new environmentally friendly, cheap, available and renewable agricultural product, Cordia millenii as an adsorbent.

\section{MATERIALS AND METHOD}

The Cordia milleni was sourced from Oke-Ado Sawmill in Ibadan, Oyo State of Nigeria (Plate 1). It was identified at the herbarium unit of Forestry Research Institute of Nigeria (FRIN) and thereafter cleaned with tap water to remove dirt and other contaminants that might adhere to it. The wood samples were air-dried for one week to reduce the moisture content. Dried woods were weighed and pyrolyzed at $500^{\circ} \mathrm{C}$ for 120 mins in a bioreactor at FRIN). The carbonized wood (Fig. 2) was crushed into powder particle and sieved into $1.18 \mathrm{~mm}$ size and thoroughly washed in distilled water to prevent further contamination (Ajayi-Banji et al. 2017). The wet char was thereafter oven dried at $120^{\circ} \mathrm{C}$ for 12 hours. Char was impregnated with zinc chloride salt based on a mass ratio suggested by Das et al., (2015). The slurries of the carbon were properly mixed and kept for about 24 hours for the $\mathrm{ZnCl}_{2}$ to soak on its surface and oven dried at $100^{\circ} \mathrm{C}$ for 24 hours. Filtrates (char) were washed in distilled water and oven dried for 12 hours at $120^{\circ} \mathrm{C}$ and stored for further studies in accordance with Bolade and Sangodoyin, (2018) procedure. Structural pattern of activated carbon derived from cordia milleni was examined using the SEM machine. A batch study was conducted on wastewater at natural $\mathrm{pH}$ of effluent (3.81) at room temperature. The study was carried out at room temperature to be representative of environmentally relevant conditions (Desta, 2014). The textile wastewater was obtained from Itoku textile dyeing industry in Itoku area, Abeokuta South Local Government Area of Ogun State, Nigeria. Grab sampling method was the mode for collecting the wastewater for this study. The wastewater was collected in a sterilised 5 Liters container. The container was rinsed three times with wastewater before filling to the brim and firmly capped. The wastewater was temporary stored under standard conditions. $6 \mathrm{~g}$ of adsorbents was put in 200 $\mathrm{ml}$ of wastewater sample. The flask containing raw wastewater samples was shaken intermittently for attainment of adsorption equilibrium.

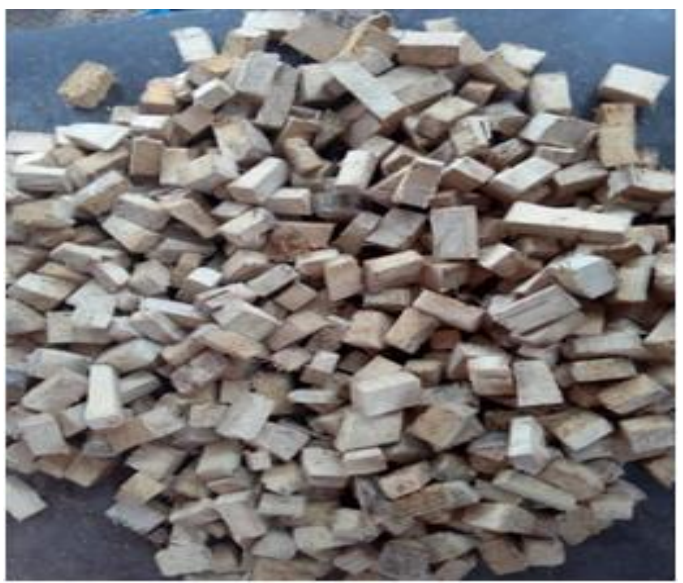

Plate 1: Cordia milleni used for activated carbon

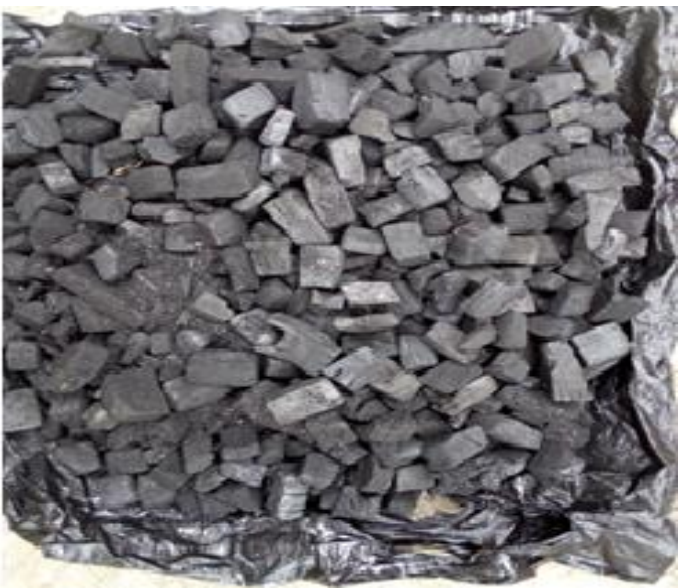

Plate 2: Pyrolysed Cordia milleni

It was assumed that the applied shaking speed allows all the surface area of the adsorbents to be in contact with the ions in the wastewater during the experiments (Desta, 2014).

Effects of contact time on pollutants removal efficiency was determined over an interval of 30 minutes for 120 minutes and thereafter, the treated wastewater was filtered through filter paper (Whatmann no. 44) and influent collected after 30, 60, 90 and 120 minutes contact time. Sorbates (contaminants) concentrations in textile wastewater sample before and after treatment were investigated in replicates using standard methods. Mean values of replicates were analysed in the study. Yield and $\mathrm{pH}$ of adsorbent were determined before and after activation according to ASTM methods.

Removal efficiency was evaluated as follows: 
Removal efficiency $=\frac{(C i-C e)}{C i} \times 100 \quad 1$

Where, Ci (mg/l) represents initial concentration of effluents before process of adsorption; Ce (mg/l) represents residual concentration after adsorption of effluents

\section{RESULTS AND DISCUSSION}

Yield and $\mathrm{pH}$ of the adsorbent: Percentage yield of Cordia millenii after carbonisation at a temperature of $500^{\circ} \mathrm{C}$ for 2 hours was $24.5 \%$. The result was in close conformity with the yield of oak tree branch of $28.6 \%$ carried out at $500^{\circ} \mathrm{C}$ in a study by Jindo et al., (2014). It was observed that biochar yield was affected by carbonisation temperature and the type of feedstock. Abugu et al., (2015) observed that the percentage yield reduced as the temperature increases even when carbonized at a longer period due to increase in temperature. This results in more volatile components of the precursor materials being lost thereby decreasing the percentage yield (Abechi, 2013). The $\mathrm{pH}$ value of non-activated Cordia milleni carbon (CMC) was 9.82 indicating that the solution of the char is weakly alkaline. After activation and thorough washing in distilled water, sample $\mathrm{pH}$ of the char became slightly acidic being 6.75 .

Structural pattern: Typical SEM of produced adsorbent from Cordia millenii is shown in Figure 1. The pore structures were evident at $20 \mu \mathrm{m}$ and interconnected with enlarged porosity of mean diameter size of $9.28 \pm 1.22 \mu \mathrm{m}$.

Removal efficiency studies for contaminants in textile wastewater: The mean concentration of heavy metals in influent and effluent textile wastewater and removal efficiency for activated Cordia millenii carbon are shown in Tables 1 and 2. The removal efficiency of the CMC adsorption indicated its' ability to remove more than $50 \%$ for all the heavy metal studied at 30 minutes contact time. Manganese removal efficiencies were $74.00,75.59,78.34$ and $81.72 \%$ at $30,60,90$ and 120 minutes contact time respectively. The carbon was able to reduce manganese concentrations below the acceptable WHO limits at 30 minutes contact time.

The result indicated that manganese has a high mobility to the surface of the activated CMC. The general trend for experimental carbon and heavy metal studied showed contact time and pore size of the adsorbent influence removal efficiency throughout the period of the experiment though the adsorbent displayed different sorption tendencies with respect to heavy metals.

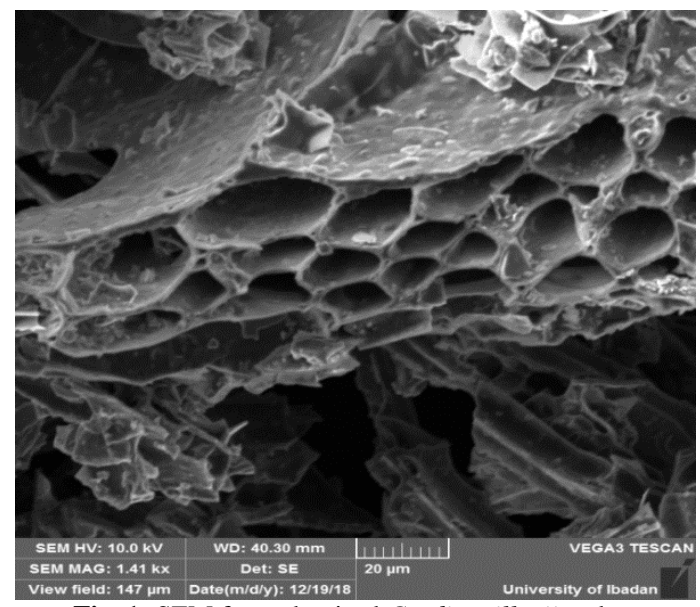

Fig. 1: SEM for carbonised Cordia millenii carbon

Table 1: Mean concentration of heavy metals in treated and untreated textile effluent

\begin{tabular}{lccccc}
\hline \multirow{2}{*}{$\begin{array}{l}\text { Heavy } \\
\text { Metals }\end{array}$} & \multirow{2}{*}{$\begin{array}{c}\text { Untreated } \\
(\mathrm{mg} / \mathrm{l})\end{array}$} & $\begin{array}{c}30 \\
\text { mins }\end{array}$ & $\begin{array}{c}60 \\
\text { mins }\end{array}$ & $\begin{array}{c}\text { T0 } \\
\text { mins }\end{array}$ & $\begin{array}{c}120 \\
\text { mins }\end{array}$ \\
\hline $\mathrm{Fe}$ & 8.99 & 3.73 & 3.55 & 3.37 & 3.28 \\
$\mathrm{Cr}$ & 5.84 & 2.14 & 2.11 & 2.01 & 1.94 \\
$\mathrm{Cd}$ & 1.44 & 0.63 & 0.53 & 0.33 & 0.29 \\
$\mathrm{Zn}$ & 3.85 & 1.66 & 1.63 & 1.45 & 1.35 \\
$\mathrm{Mn}$ & 14.5 & 3.77 & 3.54 & 3.14 & 2.65 \\
\hline
\end{tabular}

Table 2: Removal efficiency for activated carbon derived from

\begin{tabular}{lcccc}
\multicolumn{5}{c}{ Cordia millenii } \\
\hline Heavy & \multicolumn{4}{c}{ Removal Efficiency \% } \\
Metals & 30mins & $60 \mathrm{mins}$ & $90 \mathrm{mins}$ & 120mins \\
\hline $\mathrm{Fe}$ & 58.51 & 60.51 & 62.51 & 63.52 \\
$\mathrm{Cr}$ & 63.36 & 63.87 & 65.58 & 66.78 \\
$\mathrm{Cd}$ & 56.25 & 63.19 & 77.08 & 79.86 \\
$\mathrm{Zn}$ & 56.88 & 57.66 & 62.34 & 64.94 \\
$\mathrm{Mn}$ & 74.00 & 75.59 & 78.34 & 81.72 \\
\hline
\end{tabular}

The effect of different contact time of activated CMC on the percentage removal for turbidity, total suspended solids, nitrate and phosphate is shown in Figure 2. The percentage removal with increasing contact time increased from 62.13- 67.75\%, 70.04$74.17 \%$, 58.14- $63.95 \%$ and $44.09-53.75 \%$ for turbidity, nitrate, total suspended solids and phosphate respectively. The removal percentage was more than $50 \%$ at the first 30 minutes of the sorption process for nitrate, turbidity and TSS, which might be attributed to strong interaction between the adsorbents and these contaminants, and more adsorption sites at the initial stage. Gulipalli, (2011) noted that a large number of vacant surface sites were available for the adsorption during the initial stage and with the passage of time, the remaining vacant surface sites are difficult to be occupied due to repulsive forces between the solute molecules on the solid phase and in the bulk liquid phase. The reason for the removal of these contaminants could also be attributed to the electrically unsaturated sites achieved through chemical activation with zinc chloride. 


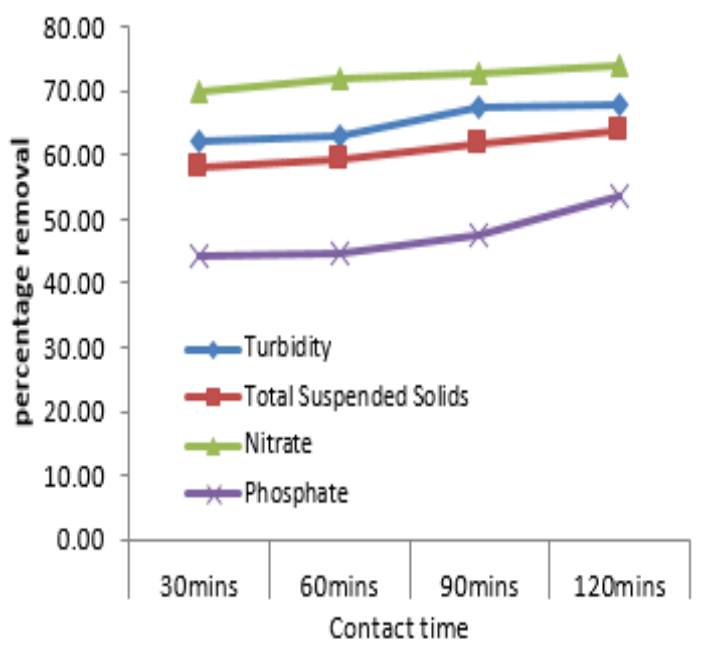

Fig 2: Effect of CMC contact time on \% reduction of contaminants

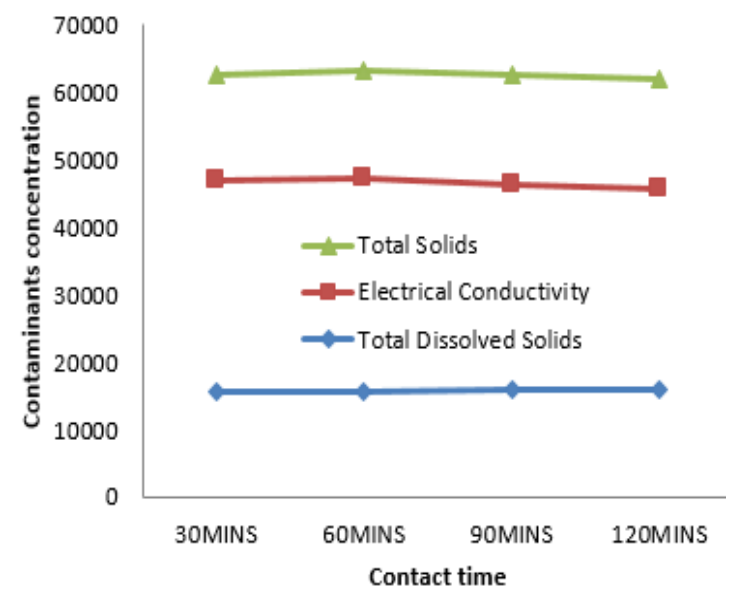

Fig 3: CMC Contact time effect on concentration of other contaminants

The Electrical Conductivity (EC) and Total Dissolved Solids (TDS), of treated effluent increased with increase in time up till 120 minutes contact time when a slight decrease was observed, as shown in Fig. 3. There was increase in total solids (TS) due to high increase in TDS. The increase in these parameters was due to the partial dissolution and possible interaction between the activated carbon from Cordia millenii and the constituents of the treated wastewater. The result is in conformity with the findings of Bolade and Sangodoyin, (2018) The increase in electrical conductivity of the wastewater could be attributed to residual salts from activation of precursor and hydrogen ions found in the precursor material (Cordia millenii). The zinc chloride salt used to activate the biochar contained zinc ions $\left(\mathrm{Zn}^{+}\right)$and chloride ions $\left(\mathrm{Cl}^{-}\right)$held together in crystals. These ions broke apart into aqueous solution of zinc and chloride ions which conducted electrical current in water. Conductivity is dependent on water salinity and total dissolved solids (Talley, 2000).
Conclusion: The activated carbon adsorbent derived from Cordia millenii is effective for the reduction of heavy metals, nitrate, phosphate, sulphate, Total Suspended Solids (TSS), turbidity. The carbon was able to reduce manganese concentrations below the acceptable WHO limits at 30 minutes contact time indicating that the carbon has high affinity for manganese. The adsorbent was not able to reduce total dissolved solids and conductivity because of the residual ions present in the activated carbon indicating that the treated wastewater cannot be reused for irrigation purpose.

\section{REFERENCES}

Abechi, SE; Gimba, CE; Uzairu, A; Dallatu, YA (2013). Preparation and Characterization of Activated Carbon from Palm Kernel Shell by Chemical Activation. Res. J. Chem. Sci. 3:54-61

Abugu, HO; Okoye, PAC; Ajiwe, VIE; Omuku, PE; Umeobika, UC (2015). Preparation and Characterization of Activated Carbon Produced from Oil Bean (Ugba or Ukpaka) and Snail Shell. J. Environ. Analyt. Chem. 2(6):1-17.

Adie, DB; Okuofu, CA; Osakwe C (2012). Isothermal and Batch Adsorption Studies of the Use of Borassus aethiopium and Cocos nucifera for Wastewater Treatment. Am. Int. J. Con. Res. 2(7):119-130.

Ajayi-Banji, .A; Sangodoyin, AY; Ijaola, OO (2015a). Coconut Husk Char Biosorptivity in Heavy Metal Diminution from Contaminated Surface Water. $J$. Eng. Stud. Res. 21 (47):169-215.

Ajayi-Banji, A; Ogunlela, A; Ogunwande, G (2017). Investigation of Locust Bean Husk Char Adsorbability in Heavy Metal Removal. Res. Agr. Eng. 63(1)29-35.

Ajayi-Banji, AA; Ewemoje, TA; Ajimo, AA (2015b). Efficacy of Locust Beans Husk Char in Heavy Metal Sequestration. Environ. Res. Eng. and Mgt. 71(4):5-10.

Badrealam, S; Roslan, FS; Dollah, S; Bakar, AAA; Handan, R (2020). Exploring the Eggshell from Household Waste as Alternative Adsorbent for Heavy Metal Removal from Wastewater. AIP Conf. Proc. https://doi.org/10.1063/1.5062703

Bolade, OO; Sangodoyin, AY (2018). Adsorption and Equilibrium Studies of Textile Effluent Treatment with Activated Snail Shell Carbon. IOSR J. Environ. Sci. Toxi. Food Tech. 12(4):26-33. 
Chen, DZ; Zhang, JX; Chen, JM (2010). Adsorption of Methyl Tert-Butyl Ether Using Granular Activated Carbon, Equilibrium and Kinetic Analysis. Int. J. Environ. Sci. Tech. 7(2)235-242.

Coker, A; Sangodoyin, AY; Sridhar, M; Booth, C; Olomolaiye, P; Hammond, F (2009). Medical Waste Management in Ibadan, Nigeria: Obstacles and Prospects. Wst. Mgt. 29:804-808

Das, D; Samal, DP; Melkap, BC (2015). Preparation of Activated Carbon from Green Coconut Shell and Its Characterization. J. Chem. Eng. Pro. Tech. Doi: 10.4172/2157-7048.1000248.

Desta, MB (2014). Batch adsorption experiments: Langmuir and Freundlich Isotherm Studies for the Adsorption of Textile Metal Ions onto Teff Straw (Eragrostis tef) Agricultural Waste. J. of thermodynamics. DOI: 10.1155/2013/375830.

Gimba, CE; Bahago, NA (2004): Adsorption of Cupper, Cadmium and Chromium using Activated Carbon from Arachis hypogea Shells. Chem. J. 2004: 208-213.

Gulipalli, CS; Rasad, BP; and wasewar, KL (2011). Batch Study, Equilibirum and Kinetics of Adsorption of Selenium Using Rice Husk Ash (RHA). J. Eng. Sci. Tech. 6(5)586-606.

Hassan, MM; Carr, CM (2020). Biomass-derived Porous Carbonaceous Materials And Their Composites as Adsorbents for Cationic and Anionic Dyes: A Review. Chemosphere, https://doi.org/10.1016/j.chemosphere.2020.12908 7.

Ijaola, O.O., Ogedengbe, K; Sangodoyin, A.Y. (2013). On the Efficacy of Activated Carbon Derived from Bamboo in the Adsorption Of Water Contaminants. Int. J. Eng. Inv. 2(4):29-34.

Jindo, K; Mizumoto, H; Sawada Y; SanchezMonedero MA; Sonoki T (2014). Physical and Chemical Characterization of Biochars Derived from Different Agricultural Residues. Biogeosciences, 11:6613-6621.

Kant, R (2011). Textile Dyeing Industry an Environmental Hazard. Nat. sci. 4 (1): 22-26.

Lellis, B; Fávaro-Polonio, CZ; Pamphile, JA; Polonio, JC (2019). Effects of Textile Dyes on Health and the Environment and Bioremediation Potential of Living Organisms. Biotechnol. Res. Innov. 3:275290.
Mohammed, AR; Mohammadi, M; Darzi GN (2010). Preparation of carbon molecular sieve from lignocellulosic biomass: A review. Ren. Sustain. Engy. Revs. 14(6); 1591-1599.

Muluken, MF (2014). Heavy Metal Concentration in Effluents Of Textile Industry, Tikur Wuha River and Milk of Cows Watering On this Water Source, Hawassa, Southern Ethiopia. Res. J. Environ. Sci. $8: 422-434$.

Okuo, J; Oviawe, AP (2007). Selective Sorption of Mixed Heavy Metal Ions Using Cassava Fiber Modified With Citric Acid. J. Chem. Soc. Nig. 32(2):247-253.

Okuo, JM; Ozoiko, AC (2001): Adsorption of Lead and Mercury ions on Chemically Treated Periwinkle Shells. J. Chem. Soc. Nig. 26(1):60-65.

Omotosho, OA; Ewemoje, TA (2020). Sequential Peroxide-Oxidation and Adsorption Treatment of Cassava Processing Wastewater: Prospects and Limitations in Augmentation of Water Budgeting Practices. Open. J. of Environ. Res. 1(1): 47-58

Reuben, NO; Miebaka, JA (2008). "Chromium (VI) adsorption Rate in the Treatment of Liquid Phase Oil Based Drill Cuttings". Afr. J. Env. Sci. and Tech. 2(4):68-674.

Sangodoyin, AY; Ajayi-Banji, AA (2013). Utilization of Abattoir Solid Wastes as Biosorbents for Surface Water Treatment Int. J. Eng. Inv. 2(11)4247.

Slokar, YM; Marechal MA (1998). Methods of Decoloration of Textile Wastewaters, Dyes Pigment. 37:335-356.

Talley, L (2000). Properties of seawater (lecture 2): Introduction to Physical Oceanography. Retrieved from http://sam.ucsd.edu/sio210/lect 2/lecture2.html, accessed $16^{\text {th }}$ May, 2020.

Yargicoglu EN; Sadasivam BY; Krishna RR; Spokas K (2014). Physical and Chemical Characterization of Waste Wood Derived Biochar. Wst. Mgt. Elsevier. 36(2015):256-268. 